\section{Commentary: Watch out for WATCHMAN device failures}

\author{
Alison F. Ward, MD, and Richard Lee, MD, JD, MBA
}

In this edition of JTCVS Techniques, Palmer and colleagues $^{1}$ present a series of 5 patients with failed WATCHMAN (Boston Scientific, Plymouth, Minn) devices requiring surgical intervention. WATCHMAN device failure is often treated with anticoagulation to prevent thrombotic complications of a malpositioned device and to reduce the stroke risk associated with the patient's atrial fibrillation.

Device failure in this series was due to peri-device leak, dislodgement, or thrombus formation, and all patients developed bleeding complications from anticoagulation. Operative indications are not exactly clear, but it appears that 3 patients had bleeding complications, 1 of whom had multiple thrombi, and 2 patients had severe mitral regurgitation (MR).

In 3 patients, the device was explanted and the left atrial appendage (LAA) excluded with either suture or with the AtriClip (AtriCure Inc, Mason, Ohio). In 1 patient, the device remained and the LAA was excluded with the AtriClip and in another patient the device was excluded with a pericardial patch. LAA occlusion was $100 \%$ successful - there was no flow or residual stump of the LAA; all patients underwent a maze procedure at the time of operation.

Several questions arise from this case series. First, why did 3 of these patients require valve replacements? Did the WATCHMAN device cause these valve pathologies and if not, shouldn't these patients have been referred for

\footnotetext{
From the Division of Cardiothoracic Surgery, Department of Surgery, Medical College of Georgia, Augusta University, Augusta, Ga.

Disclosures: The authors reported no conflicts of interest.

The Journal policy requires editors and reviewers to disclose conflicts of interest and to decline handling or reviewing manuscripts for which they may have a conflict of interest. The editors and reviewers of this article have no conflicts of interest.

Received for publication Aug 31, 2020; revisions received Aug 31, 2020; accepted for publication Sept 5, 2020; available ahead of print Sept 15, 2020.

Address for reprints: Richard Lee, MD, JD, MBA, Department of Surgery, Medical College of Georgia, 1120 15th St, BA-4300, Augusta, GA 30912 (E-mail: richardleemdmba@gmail.com or RICKLEE@augusta.edu).

JTCVS Techniques 2020;4:165-6

2666-2507

Copyright (C) 2020 The Authors. Published by Elsevier Inc. on behalf of The American Association for Thoracic Surgery. This is an open access article under the CC BY-NCND license (http://creativecommons.org/licenses/by-nc-nd/4.0/).

https://doi.org/10.1016/j.xjtc.2020.09.001
}

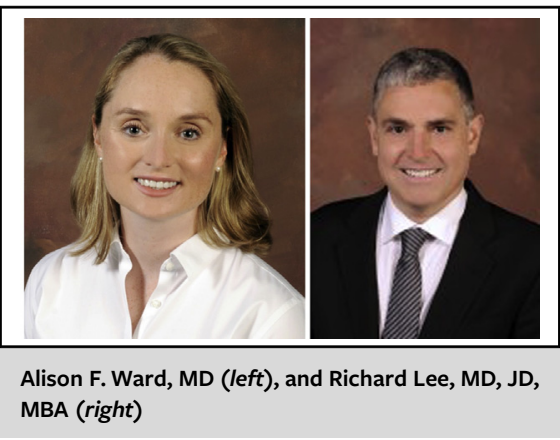

\author{
CENTRAL MESSAGE \\ WATCHMAN device failure re- \\ quires a range of surgical ap- \\ proaches described in this series. \\ Long-term data and additional \\ patient and operative details \\ would help define optimal surgi- \\ cal management.
}

surgical valve treatment and maze as the initial treatment? If the valve pathologies were caused by the device, it would be interesting to see on echocardiography how the device caused MR or aortic valve disease; there are case reports in the literature of MR and aortic stenosis caused by the WATCHMAN device. ${ }^{2,3}$ Second, while the immediate postoperative echocardiography findings are promising, we know that most failures occur late. ${ }^{4}$ This series would be strengthened by long-term imaging confirmation of LAA occlusion. Third, 2 of the patients remained on anticoagulation for 6 months; this seems unusual since both of the patients had preoperative bleeding complications. If the anticoagulation is for prevention of thromboembolism after bioprosthetic valve replacement, then why was one of the patients on rivaroxaban, which is not the recommended anticoagulant, and both were anticoagulated for 6 months, which is on the longer end of the recommended 3-6months? ${ }^{5}$ Finally, the authors include a supplemental video, which nicely shows a video-assisted thoracoscopic surgery technique for LAA exclusion with the AtriClip while keeping the device in place. This approach, as the authors comment in their conclusions, works well when there is no atrial thrombus or protrusion of the device into the left atrium. But when those criteria are not met, a robotic or right mini-thoracotomy approach could be equally effective while providing patients with the benefit of a minimally invasive operation. 
This series is an excellent summary of the types of WATCHMAN device failures and varied surgical approaches to address these failures and eliminate the LAA as a source of stroke. We encourage the authors to elaborate on this series with more patient and operative details to further understand the optimal surgical management of these complex WATCHMAN device failures.

\section{References}

1. Palmer S, Romano MA, Bolling SF, Fukahara S. Surgical strategies for a failed watchman device. J Thorac Cardiovasc Surg Tech. 2020;4:160-4.
2. Deng H, Liao H, Liu Y, Chen S, Xue Y, Zhan X, et al. Acute heart failure caused by dislocation of a WATCHMAN left atrial appendage occluder. JACC Cardiovasc Interv. 2016;9:e97-9.

3. El-Gabry M, Shehada SE, Wendt D, Mourad F. Emergent surgical removal of a migrated left atrial appendage occluder. Eur J Cardiothorac Surg. 2018;54:191-2.

4. Lee R, Vassallo P, Kruse J, Malaisrie SC, Rigolin V, Andrei AC, et al. A randomized, prospective pilot comparison of 3 atrial appendage elimination techniques: internal ligation, stapled excision, and surgical excision. J Thorac Cardiovasc Surg. 2016;152:1075-80.

5. Nishimura RA, Otto CM, Bonow RO, Carabello BA, Erwin JP III, Fleisher LA, et al. 2017 AHA/ACC focused update of the 2014 AHA/ACC guideline for the management of patients with valvular heart disease: a report of the American College of Cardiology/American Heart Association task force on clinical practice guidelines. J Am Coll Cardiol. 2017;70:252-89. 